\title{
Making regional facility location decisions: the example of Hospital do Oeste Norte, Portugal
}

\author{
Jorge Gonçalves ${ }^{1}$, J. Antunes Ferreira ${ }^{1}$, Beatriz Condessa ${ }^{1}$ \\ ${ }^{1}$ Centre for Urban and Regional Systems, Instituto Superior Técnico, Lisboa, Portugal
}

\begin{abstract}
This paper seeks to contribute to the debate on the decision-making process for the location of large public facilities, responding to the growing demand for greater rationality in public investment whilst still offering services of quality and addressing the problem of spatial friction. The specific problem analysed in this paper is the need to define the best location for a public hospital in a particular region of Portugal. The singularity of the approach adopted lies above all in the segmentation into macro-location and micro-location.
\end{abstract}

Keywords: public facility, macro-location, micro-location, local development, hospital, Portugal.

The problem of public facility location

The problem of location is a question that is always present, regardless if it concerns the rationality of private investment (where correct location contributes to profit maximisation) or public interest (where the offer of superior collective goods and services depends on the just search for social and territorial equity) (Owen and Daskin, 1998; Hare and Barcus, 2007). In the latter case, the goods or service in question may be provided, either by the public or the private sector, but the Government/State guarantees all financial considerations needed to cover the gap between the collective interest and economic viability (Kenbur and Venables, 2005). However, in the case of pure private investment, the strife for a fair distribution of social and territorial equity does not exist, as the concern is merely reaching those that can justify the cost of the service provision, i.e. areas where profits can be maximised are favoured (Malczewski and Ogryczak, 1995). As far as public investment aimed at meeting the fundamental needs of the population is concerned, albeit in a context of economic rationality, universal access must be guaranteed (McGrail and Humphreys, 2009). Even if public-private partnerships have to be established for that purpose and programming criteria have to be defined to guide the investment (Ross and Soland, 1980; DGOTDU, 2002; Delgado and Sendra, 2004).

\footnotetext{
Corresponding author:

Jorge Gonçalves

Centre for Urban and Regional Systems, Instituto Superior Técnico Avenida Rovisco Pais 1, 1049-001 Lisboa, Portugal

Tel. +351 218-418-312; Fax +351 218-409-884

E-mail: jorgemgoncalves@tecnico.ulisboa.pt
}

The necessity to satisfy the needs of the population is recognised but, at the same time, it is acknowledged that there are limits to the collective financing capacity when it comes to public facilities. For this reason, the location of public facilities becomes a central factor in the quality of life of populations and in guaranteeing an appropriate redistribution of public funds (Witter, 2012). The problem is thus generally centred around reducing spatial friction (Hyndman and Holman, 2001; Lee and Moon, 2014), but this concern is gradually replaced by others as one comes closer to defining the specific location area. The reason is that one has to consider the compatibility of the facility with the characteristics of a location option (urban dynamics, noise, pollution, congestion, availability of space, environmental sensitivity, etc.) as pointed out by Greenhut and Mai (1980). This means that one has to go through two sequential processes - macro- and micro-location - in the decision-making process that look at the location problem on different spatial levels applying differing methodologies, because they also have differing objectives.

\section{Distance from health facilities}

One of the major issues in defining locations for health facilities is guaranteeing that the most isolated local inhabitants are able to access the facility within an acceptable time frame, particularly in more urgent cases, but also in situations that require frequent visits (Hare and Barcus, 2007; McGrail and Humphreys, 2009; Field, 2000). Generally speaking, users able to choose, travel to the health facility that is situated closest to their home (Rahman and Smith, 2000). However, they may also opt for a different location, for which the 
time-distance or cost-distance is lower thanks to the design of the infrastructure network and public transport systems (Peipins et al., 2011). Decisions may also be influenced by the imposition of administrative limits on the catchment areas for the facilities in question, which could even mean greater travel distances than if the nearest facility were used. Thus, the geographical proximity logic can be challenged on administrative grounds, for reasons of the transport infrastructure network and public transport system. Finally, in cases where the individual freedom of choice is recognised by the health system, deviations from the proximity (be it geographical, temporal or in terms of cost) are possible when service quality factors, the range of services offered or even preference for certain specialist doctors or facilities are factored in. Being a time-distance away from a healthcare unit that is considered reasonable (DGOTDU, 2002) can in fact be illusory in terms of effective spatial coverage and also even in terms of population satisfaction given that there are sometimes conditions that apply to facilities, limits to resources or even situations of service congestion that can turn near into far (McGrail and Humphreys, 2009).

The existence of health infrastructures does not guarantee that they are easily accessible and, on the other hand, proximity to facilities does not guarantee that the services are readily available, as the demand may be high (Ranga and Panda, 2014). Availability and distance/proximity are factors that must be taken into consideration together (McGrail and Humphreys, 2009). Other factors, such as profession, income and education of the users, can also have an influence on the frequency with which the health services are availed of (Hare and Barcus, 2007). Hence, distance, which is variable, is not the only decisive factor when dealing with accessibility of health services. It should be treated with particular care, as it can be quantified and interpreted in many ways (Gesler and Meade, 1988; Paez et al., 2010). One can therefore establish that accessibility involves both geographical and socio-organisational aspects and amounts to more than the simple availability of resources in a given moment. It is a multi-dimensional concept that can be represented using empirical indicators (Andersen et al., 1983; Peters et al., 2008).

\section{The location requirements for large-scale public facilities}

It goes without saying that a public facility has to be conceived and located so as to best respond to the needs of its target public, but it must also comply with a number of constraints like availability, accessibility, affordability, acceptability and accommodation
(Penschansky and Thomas, 1981). The efficiency of such facilities depends on their capacity to achieve a certain service level with a minimum of operating costs. An efficient facility is, therefore, one that maximises the respective service, managing it with a limited, pre-defined budget (Truelove, 1993). In order for a public facility to achieve a high level of efficiency, criteria are applied that allow one to assess, first and foremost, the pertinence of the establishment of said facility, then its location and then its size and the range of services to be included.

In Portugal these decisive factors have been standardised and regulated for public facilities and services (DGOTDU, 2002) as follows:

(i) the justification criterion, which specifies utilisation by a minimum number of the population for viability of the facility;

(ii) the catchment criterion, which defines the maximum distance, measured in minutes or kilometres, that users have to travel;

(iii) the programming criterion, which relates to planning for the event that a facility fails to meet the needs;

(iv) the sizing criterion, which provides values for determining the surface areas required for the facility; and

(v) the location criterion, which examines the relationship with other land occupations and assesses factors such as safety, noise and urban and spatial integration.

Whilst these are consensual regulations, it is true that the specificities of regional (or even national) facilities, as well as the inclusion of other factors such as accessibility in terms of motorways, motorway tolls, traffic congestion, the environment, rivalry between local councils (reflected in the offer of sites and/or accessibility) and also the recruitment and travel needs of the human resources allocated to the facility, to name just a few, impinge on the choice. Importantly, the existence of so many diverse factors warrants the application of a more elaborate methodology with a view to ensuring greater spatial coverage with the lowest possible investment, i.e. in a highly efficient ratio (Tsou et al., 2005). It is in this context, which is new and complex, that one must look at the present issue of the location of the Hospital do Oeste Norte $(\mathrm{HON})$, which is not yet an existing facility, whereby the above-listed criteria have been deemed insufficient and one can argue the case for a hierarchical location model that:

(i) minimises the maximum overall travel time for users in the area to be covered; 
(ii) takes the cost of user travel into account;

(iii) assesses the daily travel needs of the worker universe;

(iv) takes environmental sensitivity into consideration;

(v) takes the regional surroundings into account (both from the perspective of constraints imposed by a dense urban fabric and in terms of the expected effects on the economy); and

(vi) considers the cost of the land to be used.

An application of the methodology: macro-micro location

The process of selecting the best location for a facility that requires users to travel to it has to take into consideration at least two fundamental premises: (i) the degree of regional coverage so that it responds to the demands distributed unequally throughout the region; in this case, the HON's catchment area, i.e.the municipalities of Alcobaça, Peniche, Caldas da Rainha, Nazaré, Óbidos and Bombarral; and (ii) a location that does not compromise its regional vocation, i.e. that guarantees availability of a sufficient surface area, open and congestion-free accesses with an efficient collective transport network, is on the margin of densely built or protected areas and close to human resources that are in line with for its operational needs as well as services, commerce and support facilities. Hence, in order to ensure that the two prerequisites are respected, the methodology was separated into two components: macro-location and micro-location.

Defining the macro-location involves identifying an approximate buffer zone; in this case for the establishment of a new hospital. As, in this phase, this is a coverage problem (Daskin,1995; Sridharan,1995; Serra and Marianov, 2002), the buffer area merely serves to establish that the locations for the physical location of the facility should be within this buffer area, with the actual decision on the final location involving a different approach. The HON seeks to be a structuring regional facility that will generate a considerable volume in terms of daily flux (approximately 1,000 workers, more than 300 patients per month in outpatient treatment, visits by patients' family and all other person flows necessary for the operation of a facility of this type). This can lead to positive and negative externalities in both the construction and operating phases. It is also fundamental that this approach takes into consideration:

(i) the regional spatial planning plan for the West and Tagus Valley Region (PROT OVT), which develops and implements the principles and guidelines of the National Spatial Planning Policy Programme (PNPOT), the basic document that is the strategic reference in Portugal and establishes
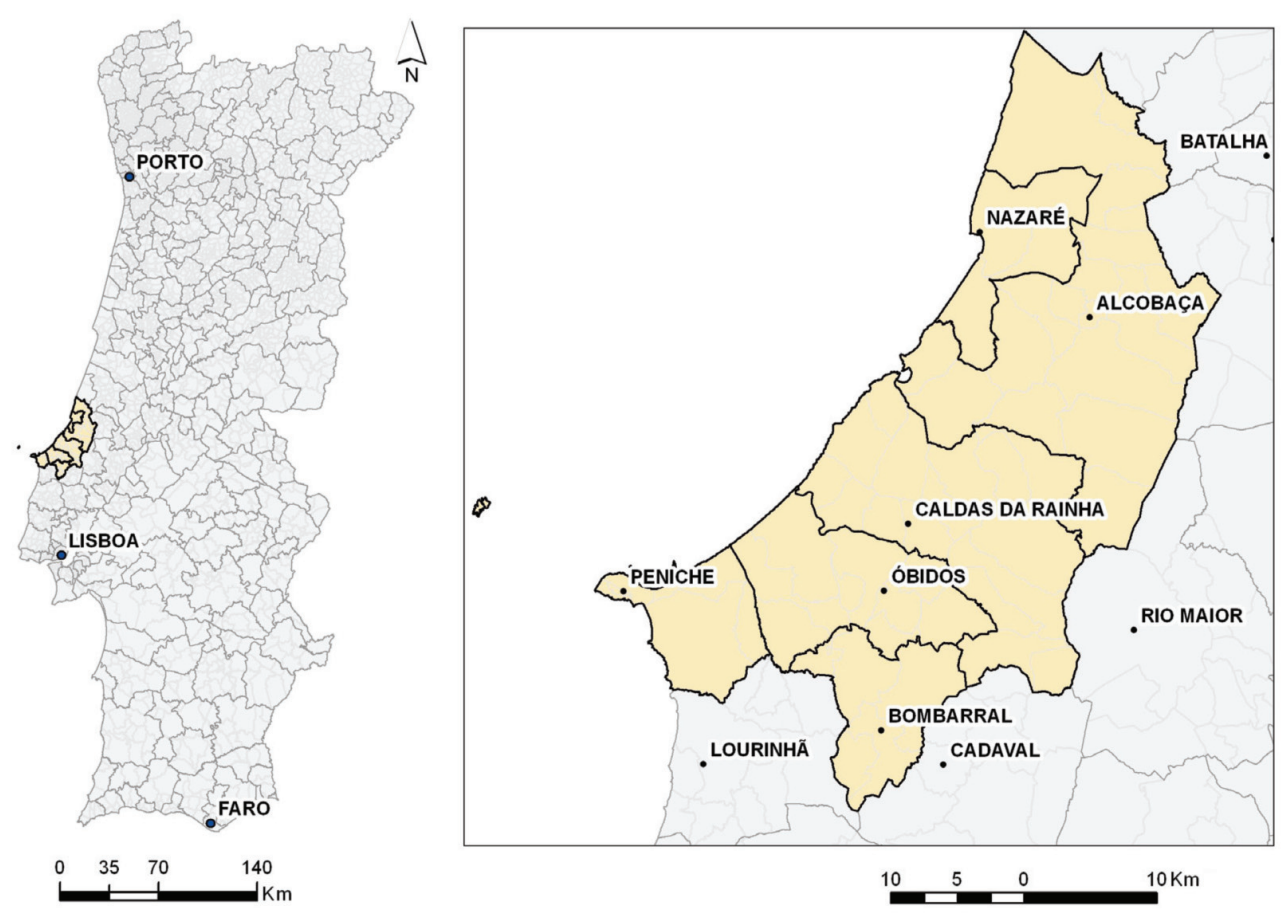

Fig. 1. Study area. 
Table 1. Criteria tree for micro-location.

\begin{tabular}{|c|c|c|}
\hline Area & Criterion & Sub-criterion \\
\hline \multirow{12}{*}{$\begin{array}{l}\text { Environment and } \\
\text { sustainability }\end{array}$} & \multirow{3}{*}{ 1. Risks } & 1.1. Susceptibility to flooding risks \\
\hline & & 1.2. Susceptibility to seismic activity \\
\hline & & 1.3. Susceptiblity to landslides \\
\hline & \multirow{2}{*}{ 2. Noise } & 2.1. Daytime-evening-night time noise \\
\hline & & 2.2. Night time noise \\
\hline & \multirow{3}{*}{ 3. Environmental constraints } & 3.1. National ecological reserve (REN) \\
\hline & & 3.2. National agricultural reserve (RAN) \\
\hline & & 3.3. Natura 2000 network \\
\hline & \multirow{3}{*}{$\begin{array}{l}\text { 4. Other constraints defined in } \\
\text { spatial planning instruments }\end{array}$} & 4.1. Watercourse easements \\
\hline & & 4.2. Basic sanitation infrastructure easements \\
\hline & & 4.3. High voltage power line easements \\
\hline & 5. Space classes & 5.1. Classification of space in the municipal master plan \\
\hline \multirow{4}{*}{$\begin{array}{l}\text { Accessibility and } \\
\text { transport }\end{array}$} & \multirow{2}{*}{ 6. Accessibility } & 6.1. Distance to upper hierarchy roads: motorway \\
\hline & & 6.2. Distance to upper hierarchy roads: primary road \\
\hline & \multirow{2}{*}{ 7. Transport network } & 7.1. Served by road public transport \\
\hline & & 7.2. Distance to train station \\
\hline \multirow{12}{*}{$\begin{array}{l}\text { Formal/land } \\
\text { characteristics }\end{array}$} & 8. Legal status & 8.1. Legal status \\
\hline & 9. Size & 9.1. Surface area \\
\hline & 10. Cost & 10.1. Cost of site \\
\hline & 11. Configuration & 11.1. Configuration \\
\hline & \multirow{3}{*}{ 12. Physical conditions } & 12.1. Exposure to sunlight \\
\hline & & 12.2. Slope \\
\hline & & 12.3. Geology \\
\hline & \multirow{4}{*}{ 13. Need for prior work } & 13.1. Demolition work \\
\hline & & $\begin{array}{l}\text { 13.2. Cost of adapting infrastructure systems (water supply, wastewater network, } \\
\text { energy supply and road network) }\end{array}$ \\
\hline & & 13.3. Annulment of constraints \\
\hline & & 13.4. Alterations to municipal master plan \\
\hline & 14. Civil protection & 14.1. Distance from nearest fire station \\
\hline
\end{tabular}

the principles to be observed in local plans (for example, municipal plans);

(ii) the spatial weighting of the places in the HON's catchment area, using gravity models, as these serve to characterise and predict the flows of people, goods and information throughout the space (Sen and Smith, 1995). The result of the application of gravity models can be spatialised, as the places correspond to balance points between the centres of mass taken into consideration (munici- pality seats, parish seats) in the chosen units (population, seasonal accommodation, medical consultations, amongst other issues);

(iii) concerns related with the universe of the human resources deemed indispensable for operation of the hospital and the users in general, taking into account the impact that these flows will have on energy consumption, the emission of pollutants, travel times and other factors; and

(iv) assessment of the seismic risk in the sub-region in 
question on the basis of the zones of seismic risk legally defined for Portugal.

It will be fundamentally important to analyse these aspects during the location decision process in order to minimise those aspects that are more negative and boost the more positive ones. The expected result of the macro-location process is the indication of a location area with a diameter of approximately $10 \mathrm{~km}$ within the new hospital's catchment area (see Fig. 1) that optimises the response to the analysed constraints, such as regional planning, distribution of centres of mass and impact on worker, user and supplier flows.

The micro-location process defines the specific location site on the basis of a given and finite set of alternatives for implementation of the hospital, taking as a base the $10 \mathrm{~km}$ diameter buffer zone defined in the preceding macro-location phase. The assessment methodology for the best location option includes (i) definition, systematisation, validation and weighting of criteria and sub-criteria for location selection; and (ii) assessment of the performance level of each location option for each of the criteria and sub-criteria.

At the end of the process it will be possible to assess the performance in each criterion and sub-criterion for each location alternative taken into consideration. Given that there is a wide range of criteria and sub-criteria to be applied to a varied list of alternative locations, one can speak of a multi-criteria model. For the choice of the best micro-location for the HON, in identifying the criteria (which, in some cases, are broken down into sub-criteria, i.e. broken down into important individual aspects that have to be appraised and evaluated), three fundamental levels of concerns were taken into account:

(i) the environment and sustainability, where, on the one hand, factors that could carry risks for the location of the hospital were taken into account and, on the other, one assessed the compatibility with planning options expressed in the spatial planning instruments at the local level, namely with regard to the classification of spaces and the existence of constraints identified in those plans;

(ii) accessibility and transport, assessing the relationship between the alternative locations/sites and the road network and public transport system; and

(iii) formal characteristics of the location alternatives/sites, encompassing aspects such as the surface and configuration of the land site, legal questions and preliminary works requirements that may constitute a greater onus and/or delay con- struction of the HON.

On the basis of a wide range of criteria and taking the aforementioned concerns into account, it was possible to define the criteria tree presented in Table 1.

\section{Conclusions}

The application of a specific, detailed methodology to the location decision process for a large public facility must be based on a complex hierarchy consisting of two sequential phases, namely macro-location and micro-location, and apply precise criteria and indicators that are specifically adapted to each location assessment phase. Thus, the first phase provides the best area for the location using the criteria adopted and the second phase allows to identify specifically, within that area, the best construction site.

The macro-location phase makes it possible to define an approximate location area that meets the initial objectives. The criteria used to determine this approximate area should be generic in nature and adjusted to the size of the area being analysed. In the micro-location process it should be possible to add more specific criteria, as we are no longer concerned with finding the "optimal" area from an infinite list of locations, which can be used to determine the best site option from a predefined set of valid options.

The conjugation of relative scale keys (better/worse) and geo-spatial analysis contributions (e.g. gravity centres) as well as the quantitative data (e.g. minimum travel times), amongst other resources and instruments, provide important support to the decisionmaking process.

The methodology presented here is a pertinent alternative to the adoption of stochastic-deterministic models in response to the complexity of the problem in question. Likewise, the communication process and its results for the non-scientific community are also more facilitated which is very important when there is a need to make transparent the criteria for use of public funds.

\section{References}

Andersen RM, McCutcheon A, Aday LA, Chiu GY, Bell R, 1983. Exploring dimensions of access to medical care. Health Serv Res 18, 49-74.

Daskin MS, 1995. Network and discrete location - models, algorithms, and applications. New York: John Wiley and Sons Inc.

Delgado MG, Sendra JB, 2004. Sensitivity analysis in multicriteria spatial decision-making: a review. Hum Ecol Risk Assess 
10, 1173-1187.

DGOTDU, 2002. Equipamentos colectivos. Normas para programação e caracterização de redes, $n^{\circ}$ 9, Direcção Geral do Ordenamento do Território e Desenvolvimento Urbano, Lisboa, Portugal.

Field K, 2000. Measuring the need for primary health care: an index of relative disadvantage. Appl Geogr 20, 305-332.

Gesler WM, Meade MS, 1988. Locational and population factors in health care-seeking behavior in Savannah, Georgia. Health Serv Res 23, 443-462.

Greenhut ML, Mai CC, 1980. Towards a general theory of public and private facility location. Ann Regional Sci 14, 1-11.

Hare TS, Barcus HR, 2007. Geographical accessibility and Kentucky's heart-related hospital services. Appl Geogr 27, 181-205.

Hyndman JCG, Holman CDJ, 2001. Accessibility and spatial distribution of general practice services in an Australian city by levels of social disadvantage. Soc Sci Med 53, 1599-1609.

Kenbur R, Venables AJ, 2005. Spatial inequality and development. Oxford: Oxford University Press.

Lee KS, Moon KJ, 2014. Hospital distribution in a metropolitan city: assessment by a geographical information system grid modelling approach. Geospat Health 8, 537-544.

Malczewski J, Ogryczak W, 1995. The multiple criteria location problem: 1. A generalized network model and the set of efficient solutions. Environ Plann A 27, 1931-1960.

McGrail MR, Humphreys JS, 2009. Measuring spatial accessibility to primary care in rural areas: improving the effectiveness of the two-step floating catchment area method. Appl Geogr 29, 533-541.

Owen SH, Daskin MS, 1998. Strategic facility location: a review. Eur J Oper Res 111, 423-447.

Paez A, Mercado RG, Farber S, Morency C, Roorda M, 2010. Accessibility to health care facilities in Montreal Island: an application of relative accessibility indicators from the perspective of senior and non-senior residents. Int J Health Geogr 9, 1-9.

Peipins LA, Graham S, Young R, Lewis B, Foster S, Flanagan B, Dent A, 2011. Time and distance barriers to mammography facilities in the Atlanta metropolitan area. J Community Health 36, 675-683.

Penchansky R, Thomas JW, 1981. The concept os acess: definition and relationship to consumer satisfaction. Med Care 19, 127-140.

Peters DH, Garg A, Bloom G, Walker DG, Brieger WR, Rahman $\mathrm{MH}, 2008$. Poverty and access to health care in developing countries. Ann N Y Acad Sci 1136, 161-171.

Rahman S, Smith DK, 2000. Use of location-allocation models in health service development planning in developing nations. Eur J Oper Res 123, 437-452.

Ranga V, Panda P, 2014. Spatial acess to in-patient health case in northern rural India. Geospat Health 8, 545-556.

Ross GT, Soland RM, 1980. A multicriteria approach to the location of public facilities. Eur J Oper Res 4, 307-321.

Sen A, Smith TE, 1995. Gravity models of spatial interaction behavior. New York: Springer.

Serra D, Marianov V, 2002. Location problems in the public sector. In: Facility Location - Application and Theory. Drezner Z, Hamacher HW (eds). Heidelberg: Springer, 119-150 pp.

Sridharan R, 1995. The capacitated plant location problem. Eur J Oper Res 87, 203-213.

Truelove M, 1993. Measurement of spatial equity. Environ Plann C 11, 19-34.

Tsou KW, Hung YT, Chang YL, 2005. An accessibility-based integrated measure of relative spatial equity in urban public facilities. Cities 22, 424-435.

Witter S, 2012. Health financing in fragile and post-conflict states: what do we know and what are the gaps? Soc Sci Med $75,2370-2377$. 